\title{
Insulin-like growth factor 1 blocks collagen release and down regulates matrix metalloproteinase-1, $-3,-8$, and -13 mRNA expression in bovine nasal cartilage stimulated with oncostatin $M$ in combination with interleukin $1 \alpha$
}

\author{
W Hui, A D Rowan, T Cawston
}

\begin{abstract}
Objective-To investigate the effect of insulin-like growth factor 1 (IGF1) on the release of collagen, and the production and expression of matrix metalloproteinases (MMPs) induced by the proinflammatory cytokine interleukin $1 \alpha$ (IL1 $\alpha)$ in combination with oncostatin $M$ (OSM) from bovine nasal cartilage and primary human articular chondrocytes.

Methods-Human articular chondrocytes and bovine nasal cartilage were cultured with and without IGF1 in the presence of IL $1 \alpha$ or IL1 $\alpha+$ OSM. The release of collagen was measured by an assay for hydroxyproline. Collagenase activity was determined with the diffuse fibril assay using ${ }^{3} \mathbf{H}$ acetylated collagen. The expression of MMP-1, MMP-3, MMP-8, MMP-13, and tissue inhibitor of metalloproteinase 1 (TIMP-1) MRNA was analysed by northern blot.

Results-IGF1 can partially inhibit the release of collagen induced by IL1 $\alpha$ or IL1 $\alpha$ + OSM from bovine nasal cartilage. This was accompanied by a reduced secretion and activation of collagenase by bovine nasal cartilage. IGF1 can also down regulate IL1 $\alpha$ or IL1 $\alpha+$ OSM induced MMP-1, MMP-3, MMP-8, and MMP-13 mRNA expression in human articular chondrocytes and bovine chondrocytes. It had no significant effect on the production and expression of TIMP-1 mRNA in chondrocytes.

Conclusion-This study shows for the first time that IGF1 can partially block the release of collagen from cartilage and suggests that down regulation of collagenases by IGF1 may be an important mechanism in preventing cartilage resorption initiated by proinflammatory cytokines.

(Ann Rheum Dis 2001;60:254-261)
\end{abstract}

University of

Newcastle, Newcastle

Upon Tyne, NE2 4HH,

UK

W Hui

A D Rowan

T Cawston

Correspondence to:

Dr Hui

Wang.Hui@ncl.ac.uk

Accepted 27 June which pull water into the tissue and allow it to resist compression. The intact collagen network provides a permanent framework that gives tensile strength, and allows PG to be held in the matrix. Collagen has a low turnover rate, and when degradation of collagen does occur the structural integrity of the tissue is irreversibly lost. ${ }^{12}$ The degradation of PG and collagen is a prominent feature of the cartilage loss seen in both rheumatoid arthritis (RA) and osteoarthritis (OA), and ultimately leads to joint destruction.

Chondrocytes within cartilage play an important part in maintaining the surrounding matrix by modulating the synthesis and degradation of the various components in both normal and pathological conditions. During degenerative joint diseases, such as RA and OA, chondrocytes elicit a catabolic response which exceeds anabolism of new matrix molecules. ${ }^{1}$ The expression and production of proteolytic enzymes is increased and a major role is indicated for matrix metalloproteinases (MMPs), which can degrade matrix components. $^{34}$

Current knowledge points to the involvement of MMPs in the pathological destruction of cartilage in arthritis. Collagens can be specifically cleaved by the collagenases. Three mammalian collagenases (MMP-1, MMP-8, and MMP-13) can directly cleave the Gly ${ }^{975}$ $\mathrm{Leu}^{976}$ bond on the $\alpha 1$ (II) chain, generating characteristic three quarter and one quarter length fragments. ${ }^{5}{ }^{6}$ After this cleavage the collagen fragments become susceptible to further degradation by other enzymes, such as stromelysin-1 (MMP-3) and gelatinases A and $\mathrm{B}$ (MMP-2 and MMP-9). MMP-3 is another potent enzyme in the turnover of cartilage components, in that it can cleave the $N$-telopeptide of type II collagen, which may lead to depolymerisation of type II collagen. ${ }^{78}$ MMP-3 is also an activator of other MMPs, such as MMP-1 and MMP-9..$^{10}$ All these enzymes are expressed by chondrocytes. ${ }^{311}$ These potent enzymes are controlled at key points that include the stimulation of synthesis and secretion by cytokines and growth factors, such as interleukin 1 (IL1) and tumour necrosis factor $\alpha$, and the activation of proenzyme forms. $^{3}{ }^{12}$ Tissue inhibitors of metalloproteinases (TIMPs), which are also expressed by chondrocytes, suppress the biological activity of collagenases. ${ }^{1314}$

Insulin-like growth factor (IGF) is a polypeptide with structural and functional homology to proinsulin. ${ }^{15}$ Human IGF1 and 
IGF2 play a part in growth and development of many tissues during fetal and adult life and are thus implicated in tissue hypertrophy and repair. IGF1 is known to enhance the synthesis of matrix in normal cartilage in vivo and in vitro and is recognised as one of the most important growth factors affecting the metabolism of matrix molecules found in cartilage. This growth factor enhances the synthesis of PG and collagen by chondrocytes in cartilage and maintains expression of cartilage type II collagen in the absence of serum without increasing the synthesis of type I collagen. ${ }^{16-18}$ IGF1 also blocks IL1 stimulated PG degradation and reverses the suppression of a cartilagespecific phenotype induced by IL1 $1{ }^{19-22}$ Thus it is also an important regulator in repair processes during joint disease. ${ }^{23}$ In bone IGF1 has been found to stimulate collagen synthesis and inhibit collagenase mRNA expression in bone cells and osteoblasts. ${ }^{24-26}$ The expression and synthesis of both IGF and IGF binding proteins (IGFBPs) are increased in arthritic chondrocytes. ${ }^{27}$ However, the precise mechanism by which IGF1 blocks cartilage breakdown induced by proinflammatory cytokines is not clear. Little information is available about the effect of this growth factor on the expression and production of MMPs induced by proinflammatory cytokines, such as $\operatorname{IL} 1 \alpha$, in cartilage.

We have recently shown that the combination of IL1 $\alpha$ and oncostatin M (OSM) promotes a dramatic release of $P G$ and collagen fragments from bovine, porcine, and human cartilage explants in culture. This synergistic release of collagen is accompanied by a marked up regulation of procollagenases, and their subsequent activation as well as a reduction in TIMP-1. ${ }^{28}$ Cytokines such as IL4 and transforming growth factor $\beta 1$ (TGF $\beta 1$ ) can block these effects. ${ }^{30} 31$

In this study we investigated whether, and to what degree, IGF1 influences the release of collagen fragments from bovine nasal cartilage stimulated with IL $1 \alpha$ in combination with OSM, and determined the possible mechanisms involved in the regulation of collagenases.

\section{Material and methods}

Chemicals were obtained from the following suppliers: Human recombinant IL1 $\alpha$ was a generous gift from Glaxo Group Research Ltd (Greenford, UK). Human recombinant OSM was generously supplied by Professor John Heath, Department of Biochemistry, Birmingham, UK. Human recombinant IGF1 was purchased from R\&D Systems (Abingdon, UK). All other chemical and biochemicals were commercially available analytical grade reagents obtained from Fisons (Loughborough, UK) or Merck (Poole, UK) or have been previously described..$^{28} 31$

CARTILAGE DEGRADATION ASSAY

Control culture medium was Dulbecco's modification of Eagle's medium (DMEM) containing $25 \mathrm{mM}$ HEPES (Gibco, Paisley, UK) supplemented with glutamine $(2 \mathrm{mM})$, streptomycin $(100 \mu \mathrm{g} / \mathrm{ml})$, penicillin $(100 \mathrm{U} / \mathrm{ml})$, and amphotericin B $(2.5 \mu \mathrm{g} / \mathrm{ml})$. Bovine nasal septum cartilage was held at $4^{\circ} \mathrm{C}$ overnight after slaughter. Discs were punched from $2 \mathrm{~mm}$ slices to give pieces $2 \mathrm{~mm}$ in diameter, which were washed twice in Dulbecco's phosphate buffered saline (DPBS). Three discs per well of a 24 well plate were incubated at $37^{\circ} \mathrm{C}$ in control medium $(600 \mu \mathrm{l})$ for 24 hours. Fresh control medium $(600 \mu \mathrm{l})$, with or without test reagents (four wells for each condition), was then added and the plate incubated at $37^{\circ} \mathrm{C}$ for seven days. The supernatants were harvested and replaced with fresh medium containing identical test reagents to day 1 . The experiment was continued for a further seven days. Day 7 and 14 supernatants and the remaining cartilage discs were stored at $-20^{\circ} \mathrm{C}$ until assayed. ${ }^{29}$ The viability of cartilage explants was assessed by screening for the production of lactate dehydrogenase (LDH) using the Cytotox 96 assay (Promega, Southampton, UK). This was always performed when new cytokine combinations were used with explants. No increase in LDH levels with any of the cytokine combinations was seen (data not shown). Serum is excluded from cartilage explants because it can markedly alter the metabolism of cartilage in the absence of exogenous cytokine(s). ${ }^{32}$ The absence of serum does not affect the viability of cartilage under these conditions and previous studies have shown that cartilage in serum-free culture for eight to nine days can respond to serum and other growth factors, ${ }^{33}$ and IGF1, which is present in serum, can also replace it. ${ }^{34}$ As this study investigated the effect of IGF1 on cartilage, serum was excluded from the explant culture system.

PROTEOGLYCAN AND COLLAGEN ASSAY

Media samples and papain digests of the remaining cartilage were assayed for sulphated glycosaminoglycan (as a measure of PG release) using the 1,9-dimethylmethylene blue dye binding assay. ${ }^{35}$ Hydroxyproline release (as a measure of collagen degradation) was assayed by a modification of the method as described. ${ }^{29}$ Mean (SD) total hydroxyproline measured in these experiments was 496.7 (112.0) ng/well.

COLLAGENASE AND TIMP ACTIVITY

Collagenase activity was determined with the diffuse fibril assay using ${ }^{3} \mathrm{H}$ acetylated collagen. ${ }^{36}$ Aminophenyl mercuric acetate (APMA) was added at $0.7 \mathrm{mmol} / 1$ to activate procollagenases. Assays without APMA gave an estimate of active collagenase, whereas inclusion of APMA allowed total collagenase (active + procollagenase) levels to be measured. Inhibitory activity was assayed by the addition of samples to a known amount of active collagenase in the diffuse fibril assay. This assay measures free TIMP activity but does not detect TIMP complexed to MMP. One unit of collagenase activity degrades $1 \mu \mathrm{g}$ of collagen per minute at $37^{\circ} \mathrm{C}$ and one unit of TIMP inhibits two units of collagenase by $50 \%$. 
CHONDROCYTE CULTURE

Human articular cartilage samples were collected from three patients with OA (age 65 (6)) who were undergoing total knee joint replacement surgery in a local hospital. These samples were predominately taken from areas of cartilage that appeared macroscopically normal. Both bovine and human cartilage were cut into small pieces, and treated by sequential enzyme digestion. The cartilage was first incubated at $37^{\circ} \mathrm{C}$ for 15 minutes with hyaluronidase at $1 \mathrm{mg} / \mathrm{ml}$ in DPBS. After three washes with DPBS, cartilage was incubated with $0.25 \%(\mathrm{w} / \mathrm{v})$ trypsin in DPBS for 30 minutes at $37^{\circ} \mathrm{C}$. The cartilage pieces were then incubated overnight with $3 \mathrm{mg} / \mathrm{ml}$ bacterial collagenase in DPBS at $37^{\circ} \mathrm{C}$. The chondrocytes were collected by centrifugation at $1100 \mathrm{rpm}$ for five minutes. After washing three times with DPBS, chondrocytes were incubated in DMEM containing $10 \%(\mathrm{v} / \mathrm{v})$ fetal calf serum at $1 \times 10^{6}$ cells/T-25 $\mathrm{cm}^{2}$ tissue culture flask in $3 \mathrm{ml}$ of culture medium. When the cells reached $80-90 \%$ confluence the medium was removed and the cells washed twice with DPBS, and then incubated in $3 \mathrm{ml}$ serum-free DMEM with test cytokines and growth factor for the indicated time period.

\section{NORTHERN BLOT ANALYSIS}

Total cellular RNA was isolated and purified using the RNeasy kit (Qiagen, Crawley, UK). Equal amounts $(10-20 \mu \mathrm{g})$ of RNA were fractionated on $1 \%$ agarose, $0.4 \mathrm{M}$ formaldehyde gels and stained with ethidium bromide to check for integrity. RNA was transferred to a GeneScreen Plus membrane, prehybridised for two to three hours in $50 \%$ formamide, $1 \mathrm{M}$ $\mathrm{NaCl}, 1 \times$ Denhardt's solution, $1 \%$ sodium dodecyl sulphate (SDS) and $100 \mu \mathrm{g} / \mathrm{ml}$ denatured salmon sperm DNA. Blots were probed for 18 hours at $42^{\circ} \mathrm{C}$ with full length human

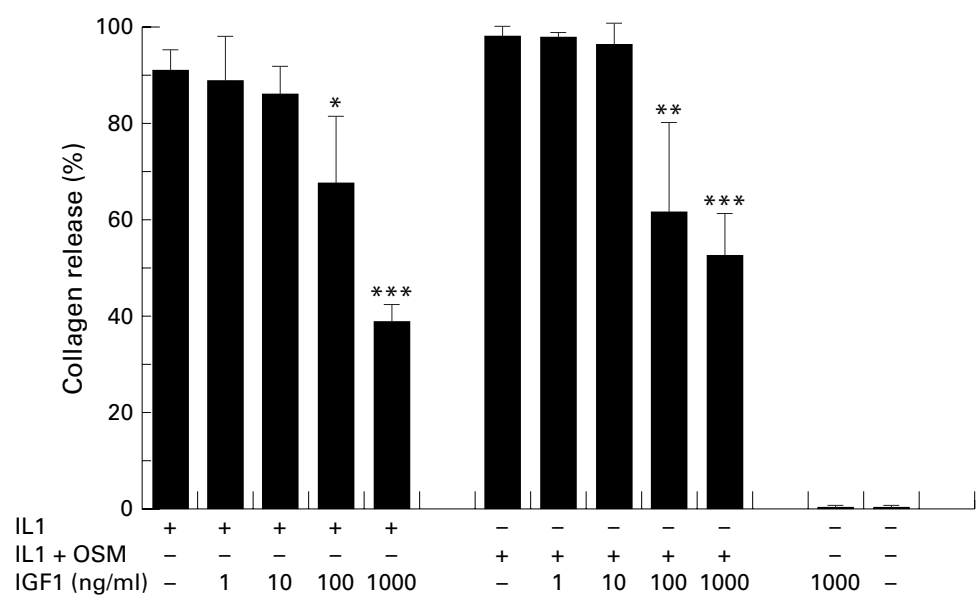

Figure 1 The effects of insulin-like growth factor 1 (IGF1) on the release of collagen fragments induced by interleukin 1a (IL1a) and IL1a + oncostatin M (OSM). Bovine nasal cartilage was cultured in serum-free medium in the presence of either medium alone, or medium containing IL1a (1 $\mathrm{ng} / \mathrm{ml})$, IL1a $(0.2 \mathrm{ng} / \mathrm{ml})+$ OSM $(2 \mathrm{ng} / \mathrm{ml})$ with IGF1 $(1-1000 \mathrm{ng} / \mathrm{ml})$ for 14 days. Media were collected at days 7 and 14. The levels of collagen fragments released into the media on days 7 and 14 were determined by the measurement of hydroxyproline as described in "Material and methods". Results shown are for the cumulative collagen release for 14 days of culture and expressed as a percentage of the total (mean (SD)). All assays were done in quadruplicate. The experiments were performed in duplicate.

Significance was analysed with respect to the cytokine compared with the cytokine +IGF1, or IGF1 compared with control. ${ }^{\star} p<0.05,{ }^{\star *} p<0.01,{ }^{\star *} p<0.001$ using $t$ test.
MMP-1, MMP-3, MMP-8, (from A Galloway, British BioTechnology, Oxford, UK), MMP-13 (from Dr V Knäuper, University of East Anglia, Norwich, UK), TIMP-1, and $1.3 \mathrm{~kb}$ rat glyceraldehyde-3-phosphate dehydrogenase (GAPDH; from Dr C Redfern, University of Newcastle, UK) cDNA probes labelled by random priming with $\alpha^{32} \mathrm{P}$ dCTP. Blots were washed twice in $2 \times$ SSC for 15 minutes at room temperature and twice for 30 minutes at $65^{\circ} \mathrm{C}$ in $2 \times$ SSC, $0.5 \%$ SDS. ${ }^{32} \mathrm{P}$ labelled cDNA-mRNA hybrids were visualised by autoradiography. The mRNA levels were measured by scanning densitometry of the bands using ImageMaster ID software (Amersham Pharmacia Biotech, Little Chalfont, UK). MMP-1, MMP-3, MMP-8, MMP-13, and TIMP-1 mRNA levels were normalised to GAPDH in the same RNA samples. ${ }^{31}$

\section{STATISTICS}

Student's $t$ test was used to compare each group with control.

\section{Results}

EFFECTS OF IGF1 ON IL1 $\alpha$ OR IL1 $\alpha+$ OSM STIMULATED PG RELEASE

PG is readily released from cartilage when stimulated with a variety of cytokines and other agents. ${ }^{19-22} 2837$ In this study we measured the release of PG at day 2 and confirmed the results of previous studies showing that IGF1 at $100 \mathrm{ng} / \mathrm{ml}$ can block the PG release induced by IL $1 \alpha$ and IL $1 \alpha+$ OSM by approximately $20-35 \%$, although increasing IGF1 to 1000 $\mathrm{ng} / \mathrm{ml}$ caused no further decrease in the amount of PG released (data not shown). ${ }^{19}{ }^{22}$

\section{LACTATE DEHYDROGENASE (LDH) ASSAY}

Normally, the viability of cartilage explants was assessed by screening for the production of $\mathrm{LDH}$ using the Cytotox 96 assay. Previously, the maximum concentrations of IGF1 used in cartilage explant cultures were in the range 500-700 ng/ml. ${ }^{23} 36$ In this experiment the maximum concentration of IGF1 used was $1000 \mathrm{ng} / \mathrm{ml}$. An LDH assay was performed with cultured bovine nasal cartilage media, controls, or treated with IL $1 \alpha$ or IL $1 \alpha+$ OSM $+/-$ IGF1 (1000 ng/ml). No increase in LDH levels with any of the cytokine combinations was found (data not shown).

EFFECT OF IGF 1 ON IL $1 \alpha$ OR IL $1 \alpha+$ OSM INDUCED COLLAGEN RELEASE

Previous studies have shown that OSM and IL1 $\alpha$ together markedly stimulated the release of collagen fragments from bovine nasal cartilage in culture by day $14 .^{28}{ }^{29}$ In this study we used this combination of cytokines to stimulate, rapidly and reproducibly, the release of collagen from cartilage. To test the ability of IGF 1 to inhibit IL $1 \alpha$ or IL $1 \alpha+$ OSM stimulated collagen release, bovine cartilage was cultured in the presence of IL $1 \alpha$ or IL $1 \alpha+$ OSM with various concentrations of IGF1 for 14 days. By day 14, over $90 \%$ collagen release 
was seen in cytokine treated cartilage samples; IGF1 produced a dose dependent inhibition of the IL $1 \alpha$ and IL $1 \alpha+$ OSM stimulated collagen release (fig 1). A statistically significant inhibition of IL $1 \alpha$ or IL $1 \alpha+$ OSM induced cartilage collagen release was seen at $100 \mathrm{ng} / \mathrm{ml} \mathrm{IGF1}$. The IL $1 \alpha$ or IL $1 \alpha+$ OSM induced collagen release was blocked by approximately $45 \%$.

EFFECT OF IGF1 ON LEVELS OF ACTIVE AND PROCOLLAGENASE IN THE MEDIA OF IL $1 \alpha$ OR IL $1 \alpha$ + OSM TREATED CARTILAGE

The media collected from IL $1 \alpha$ or IL $1 \alpha+$ OSM with or without IGF1 treated cartilage samples were assayed for the activity of collagenolytic enzymes as determined by the diffuse fibril assay using ${ }^{3} \mathrm{H}$ acetylated collagen. ${ }^{36}$ APMA was added to activate procollagenases. IL $1 \alpha$ or IL $1 \alpha+$ OSM treated cartilage samples produced high levels of active and procollagenase at day 14 . IGF1 significantly reduced both active and procollagenase activity induced by IL $1 \alpha$ or IL $1 \alpha+$ OSM, in a dose
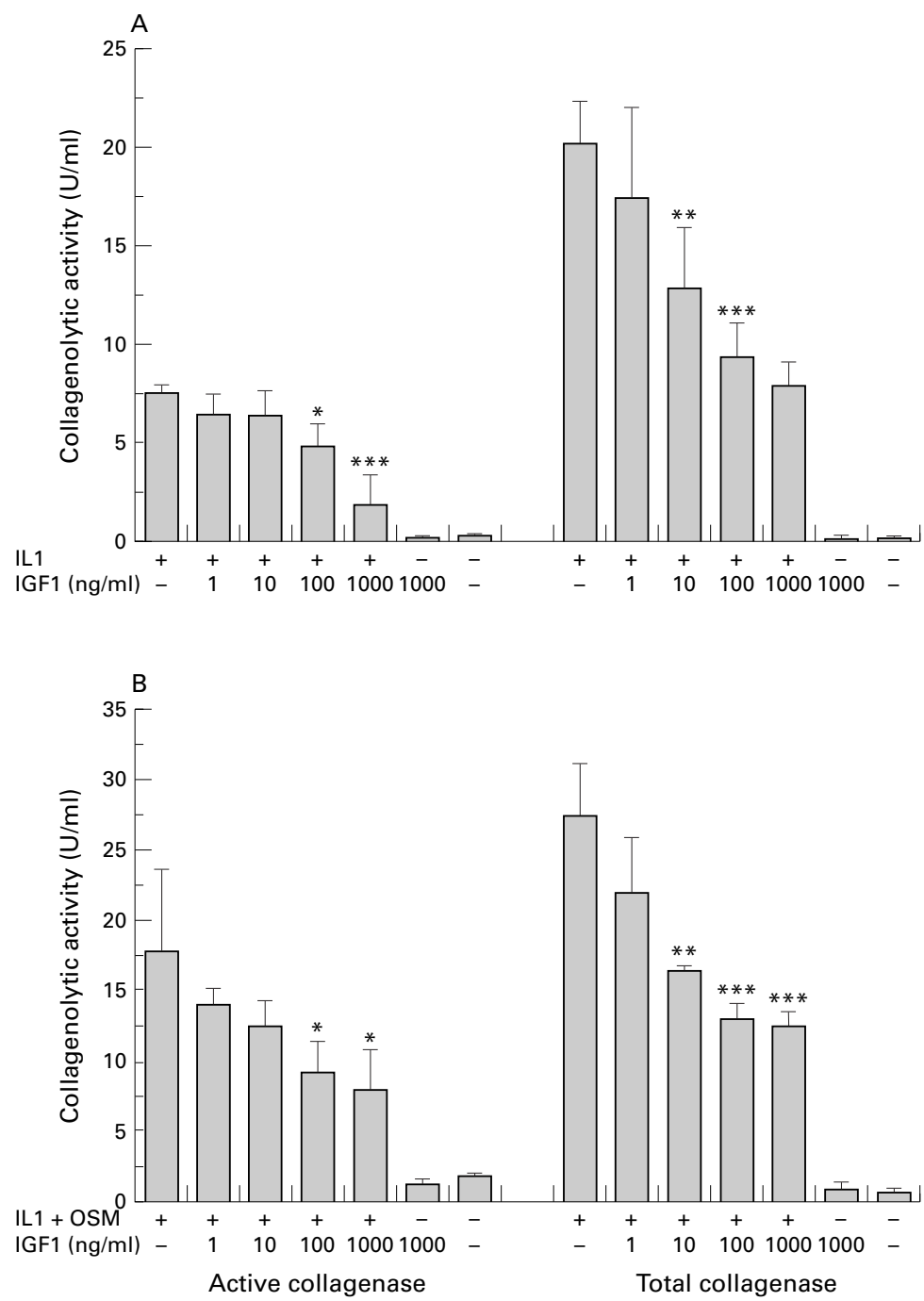

Figure 2 Effects of insulin-like growth factor 1 (IGF1) on the levels of collagenolytic activity induced by interleukin 1a (IL1a) or IL1a + oncostatin M (OSM). Bovine nasal cartilage was treated as described for fig 1. The levels of procollagenase and active collagenase activity in media removed from cultured cartilage at day 14 after stimulation with (A) IL1a and (B) IL1a + OSM, with or without IGF1, were measured as described in "Material and methods". dependent way (fig 2). The pattern of down regulation of collagenase activity correlated with the reduction in collagen release (compare figs 1 and 2).

EFFECT OF IGF1 ON TIMP INHIBITORY ACTIVITY IN THE MEDIA OF IL $1 \alpha$ OR IL $1 \alpha+$ OSM TREATED CARTILAGE

Cytokines such as TGF $\beta 1$ and OSM induce TIMP-1 synthesis and secretion in human chondrocytes. ${ }^{38}{ }^{39}$ We decided to investigate the effect of IGF1 on TIMP-1 production, which is down regulated by IL $1 \alpha$ or IL $1 \alpha+$ OSM. The media collected from cartilage treated with IL $1 \alpha$ or IL $1 \alpha+$ OSM in the presence of various concentrations of IGF1 were assayed for TIMP activity. These experiments showed no free TIMP activity in any of the media samples (data not shown). Furthermore, IGF1 alone did not alter the measurable level of TIMP activity compared with control (data not shown).

EFFECTS OF IGF1 ON THE EXPRESSION OF MMP AND TIMP MRNA IN BOVINE NASAL CHONDROCYTES

Bovine nasal chondrocytes were treated with IL $1 \alpha$, OSM, and IL $1 \alpha+$ OSM with $100 \mathrm{ng} / \mathrm{ml}$ IGF1 in serum-free medium. After 24,48 , and 72 hours, total cellular RNA was purified and transferred to a GeneScreen membrane. Blots were probed with cDNA probes for MMP-1, MMP-3, MMP-8, MMP-13, and TIMP-1. The blots showed that IL1 $\alpha$ stimulated MMP-1, MMP-3, and MMP-13 mRNA expression in a time dependent fashion (fig 3). IGF 1 can decrease IL $1 \alpha$, OSM, and IL $1 \alpha+$ OSM induced MMP-1, MMP-3, and MMP-13 mRNA expression, and also down regulate the basal MMP expression. There was no detectable MMP-8 mRNA expression in bovine nasal chondrocytes after stimulation with IL $1 \alpha$ or IL $1 \alpha+$ OSM, with or without IGF1 (data not shown). This may be because the human MMP-8 probe does not cross react with bovine MMP-8 mRNA or bovine chondrocytes express MMP-8 mRNA at levels below northern blot detection. IL $1 \alpha+$ OSM and OSM up regulated TIMP-1 expression. IGF1 had no significant effect on the expression of TIMP-1 mRNA when added alone or in combination with cytokines (fig 3 ).

EFFECTS OF IGF1 ON CYTOKINE INDUCED MMP-1, MMP-3, MMP-8, AND MMP-13 mRNA EXPRESSION IN HUMAN ARTICULAR CHONDROCYTES

Human articular chondrocytes were treated with IL $1 \alpha$, OSM, and IL $1 \alpha+$ OSM with or without IGF1 $(200 \mathrm{ng} / \mathrm{ml})$ in serum-free medium for 48 hours. Total cellular RNA was purified and transferred to a GeneScreen membrane. Blots were probed with cDNA probes for MMP-1, MMP-3, MMP-8, and MMP-13. The blots showed that IGF1 can decrease IL $1 \alpha$, OSM, and IL $1 \alpha+$ OSM induced expression of MMP-1, MMP-3, MMP-8, and MMP-13 mRNA (fig 4). 


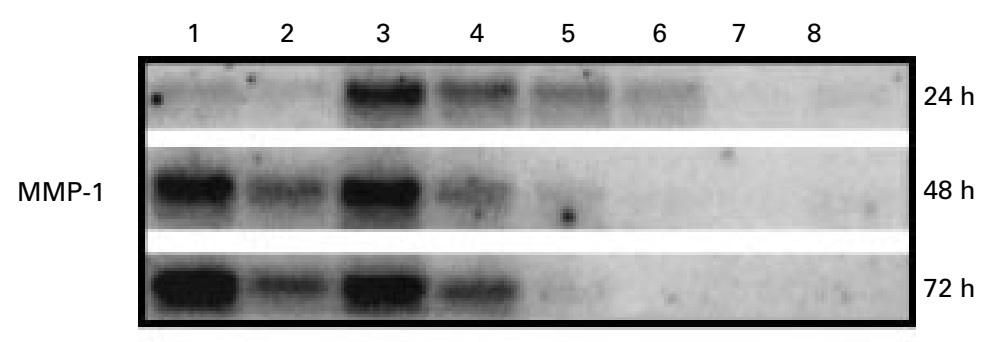

MMP-3

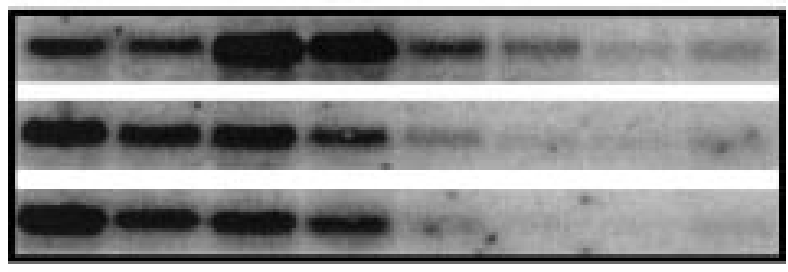

$24 \mathrm{~h}$

MMP-13
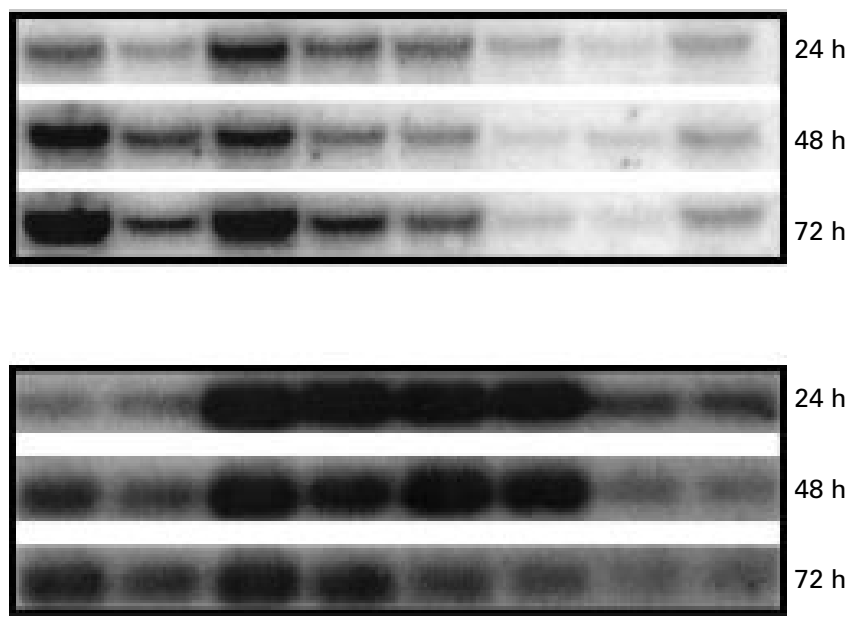

$24 \mathrm{~h}$

TIMP-1

$48 \mathrm{~h}$

\section{$72 \mathrm{~h}$}

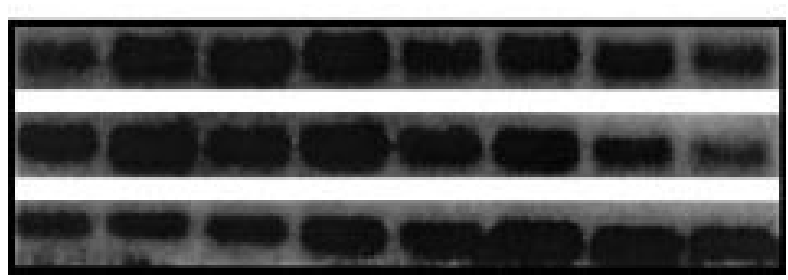

$24 \mathrm{~h}$

GAPDH

Figure 3 Effects of insulin-like growth factor 1 (IGF1) on the expression of metalloproteinase (MMP) and tissue inhibitor of metalloproteinase (TIMP) mRNA in bovine chondrocytes. Bovine nasal chondrocytes were incubated with interleukin 1a (IL1a, $1 \mathrm{ng} / \mathrm{ml})$, oncostatin $M$ (OSM; $10 \mathrm{ng} / \mathrm{ml})$ and IL1a $(0.2 \mathrm{ng} / \mathrm{ml})+O S M(2 \mathrm{ng} / \mathrm{ml})$ with IGF1 $(200 \mathrm{ng} / \mathrm{ml})$ in serum free medium for the times indicated. The expression of

$M M P-1, M M P-3, M M P-8, M M P-13$, and TIMP-1 $m R N A$ was analysed by northern blot. Lane $1=I L 1 a$; lane $2=I L 1 a+I G F 1$; lane $3=I L 1 a+O S M$; lane $4=I L 1 a+$ OSM + IGF1; lane $5=$ OSM; lane $6=$ OSM + IGF1; lane $7=I$ IGF1; lane $8=$ control .

\section{Discussion}

The major focus of this study was to investigate agents that prevent collagen breakdown. We demonstrate, for the first time, that IGF1 can partially block collagen fragment release and decrease collagenase activity induced by $\operatorname{IL} 1 \alpha$ and IL $1 \alpha+$ OSM from bovine nasal cartilage. Previously, IGF1 has been shown to enhance collagen and PG synthesis by chondrocytes and osteoblasts, and to inhibit both basal and IL1 induced degradation of PG in cartilage. ${ }^{16-22}$ Furthermore, IGF1 can successfully maintain cartilage structure and biochemistry and en- hance the repair of damaged cartilage. ${ }^{23} 3340-42$ No studies on IGF 1 blocking collagen breakdown induced by cytokines in cartilage have been reported previously. In this study we show that there is a similar pattern attenuating IL $1 \alpha$ and IL $1 \alpha+$ OSM induced collagen release and a down regulation of active and procollagenases by IGF1 in cultured bovine cartilage. This suggests that down regulation of collagenases by IGF 1 is an important mechanism in blocking the action of proinflammatory cytokines which play a part in cartilage resorption, especially collagen degradation. The protection of cartilage by IGF1 was considered to involve the prevention of production and release of collagenases or the increase in a protease activator inhibitor, ${ }^{25} 264$ but these studies are not conclusive.

MMPs are known to degrade various components of the cartilage matrix and several have been demonstrated in RA and OA tissues. ${ }^{11} 1244$ To date, most of the studies on MMP expression and production in arthritic joint tissues and cells have been observations on the effect of cytokine or growth factor alone on chondrocytes. ${ }^{35}$ Only a few studies have examined the interactions between catabolic cytokines and anabolic growth factors on the expression of MMPs in chondrocytes. TGF $\beta 1$ is known to inhibit partially IL1 stimulated cartilage degradation in vitro ${ }^{46}$ and was shown to down regulate MMP mRNA levels in osteoarthritic and normal chondrocytes. ${ }^{47}$ Interferon $\gamma$ can also block the production of IL1 stimulated collagenases in human articular chondrocytes. ${ }^{48}$ Our observations, using primary human and bovine chondrocytes, show that IGF1 can down regulate MMP-1, MMP-3, and MMP-13 mRNA expression induced by IL $1 \alpha$ and IL $1 \alpha+$ OSM. Furthermore, we found that IL $1 \alpha$ and IL $1 \alpha+$ OSM could stimulate the expression of MMP-8 in human articular chondrocytes, though the level of MMP-8 expression was relatively low compared with the expression of other MMPs. MMP-8 levels were also down regulated by IGF1 in human chondrocytes. This is consistent with the observations of Cole and coworkers when they first detected that MMP-8 mRNA was expressed in human chondrocytes. They found that although the amount of mRNA expression by either isolated human articular chondrocytes or chondrocytes within cartilage was very low, it was significantly up regulated by IL1. ${ }^{11}$ In bovine nasal chondrocytes there was no detectable expression of MMP-8 mRNA after stimulation by cytokines. This might be because the human MMP-8 probe failed to cross react with bovine MMP-8, or perhaps the level of MMP- 8 mRNA expression by bovine nasal chondrocytes was below the limit of detection. IGF1 has been previously shown to inhibit the expression of collagenase mRNAs, such as MMP-1 and MMP-13, in osteoblasts. ${ }^{25}$ This study is the first report that IGF1 can down regulate the expression and production of collagenases in chondrocytes stimulated by proinflammatory cytokines. 


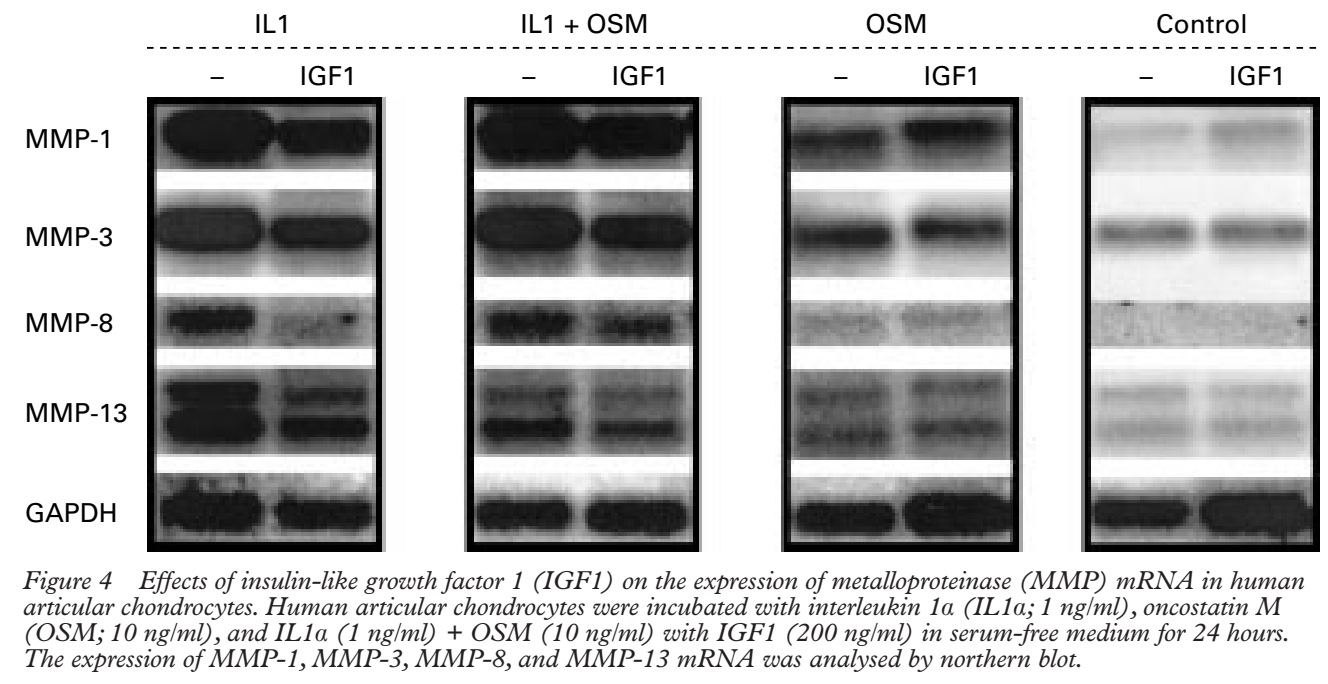

OSM is a multifunctional cytokine produced by activated $\mathrm{T}$ lymphocytes and monocytes, ${ }^{49}$ as well as rheumatoid synovial macrophages. ${ }^{29}$ It is structurally and functionally related to the IL6 family of cytokines, which includes IL6, IL1 1, leukaemia inhibitory factor, OSM, ciliary neurotrophic factor, and cardiotrophin 1 . The IL6 family of cytokines, except cardiotrophin 1, can inhibit PG synthesis in articular cartilage. ${ }^{37}$ OSM was initially proposed as a chondroprotective agent when it was found to up regulate TIMP-1 production in human articular chondrocytes, synovial fibroblasts, and synovial lining cells. ${ }^{39}$ Later studies have shown that it stimulates PG release and also inhibits PG synthesis in cartilage explants. ${ }^{37} \mathrm{~A}$ raised level of OSM in rheumatoid joints correlates significantly with synovial fluid white cell count. ${ }^{29}{ }^{50}$ More recently, studies in our laboratory have shown that the combination of IL $1 \alpha$ with OSM initiated a dramatic release of collagen from bovine, porcine, and human cartilage which correlated with increased levels of active collagenase and procollagenase and decreased levels of TIMP activity. ${ }^{29}$ In this study we combined OSM ( $2 \mathrm{ng} / \mathrm{ml})$ with IL $1 \alpha$ $(0.2 \mathrm{ng} / \mathrm{ml})$, and after 14 days' incubation over $90 \%$ collagen was released from the cartilage. At these concentrations, neither agent alone promoted collagen release (data not shown). The potency of the low concentration combination of IL $1 \alpha+$ OSM for collagen release is similar to that with $1 \mathrm{ng} / \mathrm{ml}$ IL1 $\alpha$ alone. Furthermore, there are similar levels of collagenase in the media from IL $1 \alpha+\operatorname{OSM}(0.2 / 2$ $\mathrm{ng} / \mathrm{ml})$ stimulated cartilage as from IL $1 \alpha$ (1 $\mathrm{ng} / \mathrm{ml}$ ) alone at day 14 . OSM alone, even at 10 $\mathrm{ng} / \mathrm{ml}$ in cultured bovine cartilage, did not significantly induce collagen release. Northern blot data indicated that OSM (at $10 \mathrm{ng} / \mathrm{ml}$ ) up regulated the expression of MMP mRNAs, but the potency was lower than that of IL $1 \alpha$ or IL $1 \alpha+$ OSM. IGF 1 also down regulated this expression. This agrees with the finding that when SW 1353 chondrosarcoma cells were treated with OSM alone very low MMP-1 and MMP-13 levels were produced. However, the release of the procollagenases MMP-1 and MMP-13 was potentiated with OSM in combination with IL $1 .{ }^{51}$ Clearly, the increased release of collagen from bovine nasal cartilage is due to increasing levels of active collagenases, but the precise mechanisms involved in the synergy are not yet known. The mechanism may be associated with OSM up regulating enzymes that are responsible for the initiation of activation cascades, and/or the stimulation of other catabolic cytokines.

We noted that IL $1 \alpha+$ OSM or OSM up regulated TIMP-1 mRNA expression, and that IGF1 alone or in combination with IL1 $\alpha$ or IL1 $\alpha+$ OSM did not significantly modify TIMP-1 production in chondrocytes. This is consistent with the recent report by Canalis et $a l$, where it was found that neither IGF1 nor IGF-2 modified the expression of TIMP-1, TIMP-2, or TIMP-3 mRNA in osteoblasts. ${ }^{25}$

It is known that IGF1 bioavailability is modulated by specific IGFBPs, six of which have been identified (IGFBP1-6). IGFBPs can bind to this growth factor in order to sequester it so as to prevent its binding to IGF receptors ${ }^{19}$ and IGFBP was found to inhibit IGF1 stimulated PG synthesis. ${ }^{52}$ Raised levels of IGFBP have been detected in RA and OA synovial fluids, and the production of IGFBPs by chondrocytes is increased in these disease conditions. IL1 induces secretion of IGFBPs and down regulates IGF mRNA levels in chondrocytes, which indicates that IGFBPs might accelerate cartilage destruction by blocking the protective action of IGF $1 .{ }^{19}$ Studies also found that IGFBPs can be degraded by MMP-1, MMP-2, and MMP- $3^{5354}$ and it is considered that degradation of IGFBPs by MMPs is an important step in regulating IGF bioactivity. This study clearly shows that IGF1 has a protective effect on cartilage stimulated to resorb, but previous studies have shown that human OA chondrocytes do not always respond to IGF, possibly because increased levels of IGFBP are present. ${ }^{55}$ Schouten et al showed that increased circulating levels of IGF1 were associated with osteophyte formation but not with preventing the erosion of cartilage in patients with OA of the knee. ${ }^{56}$ Thus the interactions between IGF, IGFBPs, and 
proteinases are complex in both health and disease and need further study.

IGF1 can block collagen release and decrease collagenase activity induced by IL $1 \alpha$ and IL $1 \alpha+$ OSM in bovine nasal cartilage. This is further confirmed from collagenase mRNA levels by northern blot analyses. These observations represent new biological effects for this growth factor and suggests that down regulation of collagenases by IGF 1 may be an important mechanism in preventing cartilage resorption initiated by proinflammatory cytokines.

This work was supported by the Arthritis Research Campaign and the Newcastle University Hospitals Special Trustees, UK

1 Cawston T. Tissue destruction and repair. In: Klippel JH, Dieppe PA, eds. Rheumatology. London: Mosby, 1998:1-6. 2 Hardingham TE, Fosang AJ. The structure of aggrecan an its turnover in cartilage. J Rheumatol 1995;43:86-90.

3 Shlopov BV, Lie WR, Mainardi CL, Cole AA, Chubinskaya S, Hasty KA. Osteoarthritic lesions: involvement of three different collagenases. Arthritis Rheum 1997;40:2065-74.

4 Cawston T. Matrix metalloproteinases and TIMPs: properties and implications for the rheumatic diseases. Molecular Medicine Today 1998;4:130-7.

5 Billinghurst RC, Dahlberg L, Ionescu M, Reiner A, Bourne $\mathrm{R}$, Rorabeck C, et al. Enhanced cleavage of type II collagen by collagenases in osteoarthritic articular cartilage. J Clin Invest 1997;99:1534-45.

6 Gadher SJ, Eyre DR, Wotton SF, Schmid TM, Woolley D. Degradation of cartilage collagens type II, IX, X and XI by enzymes derived from human articular chondrocytes. Matrix 1990;10:154-63.

7 Saito S, Katoh M, Masumoto M, Matsumoto S, Masuho Y. Involvement of MMP-1 and MMP-3 in collagen degradation induced by IL-1 in rabbit cartilage explant culture. Life Sci 1998;62:359-65.

8 Wu JJ, Lark MW, Chun LE, Eyre DR. Sites of stromelysin cleavage in collagen types II, IX, X, and XI of cartilage. J Biol Chem 1991;266:5625-8.

9 Suzuki K, Enghild JJ, Morodomi T, Salvesen G, Nagase H. Mechanisms of activation of tissue procollagenase by matrix metalloproteinase 3 (stromelysin). Biochemistry 1990;29:10261-70.

10 Ogata Y, Enghild JJ, Nagase H. Matrix metalloproteinase 3 (stromelysin) activates the precursor for the human matrix metalloproteinase 9. J Biol Chem 1992;267:3581-4.

11 Cole AA, Chubinskaya S, Schumacher B, Huch K, Szabo G, Yao J, et al. Chondrocyte matrix metalloproteinase-8. Human articular chondrocytes express neutrophil collagenase. J Biol Chem 1996;271:11023-6.

12 Borden P, Solymar D, Sucharczuk A, Lindman B, Cannon $\mathrm{P}$, Heller RA. Cytokine control of interstitial collagenase and collagenase-3 gene expression in human chondrocytes. J Biol Chem 1996;271:23577-81.

13 Cawston TE. Metalloproteinase inhibitors and the prevention of connective tissue breakdown. Pharmacol Ther 1996;70:163-82

14 Su S, Grover J, Roughley PJ, DiBattista JA, Martel-Pelletier $\mathrm{J}$, Pelletier JP, et al. Expression of the tissue inhibitor of
metalloproteinases (TIMP) gene family in normal and osteoarthritic joints. Rheumatol Int 1999;18:183-91.

15 Froesch ER, Schmid C, Schwander J, Zapf J. Actions of insulin-like growth factors. Annu Rev Physiol 1985;47: 443-67.

16 McQuillan DJ, Handley CJ, Campbell MA, Bolis S, Milway VE, Herington AC. Stimulation of proteoglycan biosynthesis by serum and insulin-like growth factor-I in culture bovine articular cartilage. Biochem J 1986;240:423-30.

17 Yaeger PC, Masi TL, de Ortiz JL, Binette F, Tubo R, McPherson JM. Synergistic action of transforming growth factor-beta and insulin-like growth factor-I induces expression of type II collagen and aggrecan genes in adult human sion of type II collagen and aggrecan genes in adult hum
articular chondrocytes. Exp Cell Res 1997;237:318-25.

18 articular chondrocytes. Exp Cell Res 1997;237:318-25. Demarquay D, Dumontier MF, Tsagris L, Bourguignon J, Nataf V, Corvol MT. In vitro insulin-like growth factor I
interaction with cartilage cells derived from postnatal interaction with cartilage cells derive

19 Verschure PJ, Van Noorden CJ, Van Marle J, Van den Berg WB. Articular cartilage destruction in experimental inflammatory arthritis: insulin-like growth factor-1 regulation of proteoglycan metabolism in chondrocytes. Histochem J 1996;28:835-57.

20 Goldring MB, Birkhead J, Sandell LJ, Kimura T, Krane SM. Interleukin 1 suppresses expression of cartilage-specific types II and IX collagens and increases types I and III collagens in human chondrocytes. J Clin Invest 1988;82: 2026-37.

21 Tyler J. The influence of interleukin 1 and insulin-like growth factor I on the integrity of cartilage matrix. In Grauert AM, ed. The control of tissue damage. Amsterdam: Elsevier, 1998:197-219.

22 Tyler JA. Insulin-like growth factor 1 can decrease degradation and promote synthesis of proteoglycan in cartilage exposed to cytokines. Biochem J 1989;260:543-8.
23 Chandrasekhar S, Harvey AK, Stack ST. Degradative and repair responses of cartilage to cytokines and growth factors occur via distinct pathways. Agents Actions 1993;39(suppl):121-5.

24 McCarthy TL, Centrella M, Canalis E. Regulatory effects of insulin-like growth factors I and II on bone collagen synthesis in rat calvarial cultures. Endocrinology 1989;124: 301-9.

25 Canalis E, Rydziel S, Delany AM, Varghese S, Jeffrey JJ. Insulin-like growth factors inhibit interstitial collagenase synthesis

26 Rydziel S, Delany AM, Canalis E. Insulin-like growth factor I inhibits the transcription of collagenase 3 in osteoblast I inhibits the transcription of collagenase
cultures. J Cell Biochem 1997;67:176-83

27 Middleton JF, Tyler JA. Upregulation of insulin-like growth factor I gene expression in the lesions of osteoarthritic human articular cartilage. Ann Rheum Dis 1992;51:440-7.

28 Cawston TE, Ellis AJ, Humm G, Lean E, Ward D, Curry V. Interleukin- 1 and oncostatin $\mathrm{M}$ in combination promote the release of collagen fragments from bovine nasal cartilage in cultu

29 Cawston TE, Curry VA, Summers CA, Clark IM, Riley GP, Life $P F$, et al. The role of oncostatin $M$ in animal and human connective tissue collagen turnover and its localization within the rheumatoid joint. Arthritis Rheum 1998;41: 1760-71.

30 Cawston TE, Ellis AJ, Bigg H, Curry V, Lean E, Ward D. Interleukin-4 blocks the release of collagen fragments from bovine nasal cartilage treated with cytokines. Biochim Biophys Acta 1996;1314:226-32.

31 Hui W, Rowan AD, Cawston TE. Transforming growth factor- $\beta 1$ blocks the release of collagen fragments from bovine nasal cartilage stimulated by oncostatin $\mathrm{M}$ in combination with interleukin-1. Cytokine 2000;12:765-9.

32 Sah RL, Chen AC, Grodzinsky AJ, Trippel SB. Differential effects of bFGF and IGF-I on matrix metabolism in calf and adult bovine cartilage explants. Arch Biochem Biophys 1994;308:137-47.

33 Luyten FP, Hascall VC, Nissley SP, Morales TI, Reddi AH. Insulin-like growth factors maintain steady-state metabolism of proteoglycans in bovine articular cartilage explants. Arch Biochem Biophys 1988;267:416-25.

34 Hascall VC, Handley CJ, McQuillan DJ, Hascall GK, Robinson HC, Lowther DA. The effect of serum on biosynthesis of proteoglycans by bovine articular cartilage in culture. Arch Biochem Biophys 1983;224:206-23.

35 Farndale RW, Buttle DJ, Barrett AJ. Improved quantitation and discrimination of sulphated glycosaminoglycans by use of dimethylmethylene blue. Biochim Biophys Acta 1986; 883:173-7.

36 Koshy PJT, Rowan AD, Life PF, Cawston TE. 96-well plate assays for measuring collagenase activity using ${ }^{3} \mathrm{H}-$ assays for measuring collagenase activity using

37 Hui W, Bell M, Carroll G. Oncostatin M (OSM) stimulates resorption and inhibits synthesis of proteoglycan in porcine articular cartilage explants. Cytokine 1996;8:495-500.

38 Gunther M, Haubeck HD, van de Leur E, Blaser J, Bender $\mathrm{S}$, Gutgemann I, et al. Transforming growth factor beta 1 regulates tissue inhibitor of metalloproteinases-1 expression in differentiated human articular chondrocytes. Arthritis Rheum 1994;37:395-405.

39 Nemoto O, Yamada H, Mukaida M, Shimmei M. Stimulation of TIMP-1 production by oncostatin $\mathrm{M}$ in human articular cartilage. Arthritis Rheum 1996;39: h60-6.

40 van Beuningen HM, van der Kraan PM, Arntz OJ, van den Berg WB. Protection from interleukin 1 induced destruction of articular cartilage by transforming growth factor beta: studies in anatomically intact cartilage in vitro and in vivo. Ann Rheum Dis 1993;52:185-91.

41 Morales TI. Transforming growth factor-beta and insulinlike growth factor-1 restore proteoglycan metabolism of bovine articular cartilage after depletion by retinoic acid. Arch Biochem Biophys 1994;315:190-8.

42 Rogachefsky RA, Dean DD, Howell DS, Altman RD. Treatment of canine osteoarthritis with sodium pentosan polysulfate and insulin-like growth factor-1. Ann N Y Acad Sci 1994;732:392-4.

43 Padayatty SJ, Orme S, Zenobi PD, Stickland $\mathrm{MH}$, Belchetz PE, Grant PJ. The effects of insulin-like growth factor-1 on plasminogen activator inhibitor-1 synthesis and secretion: results from in vitro and in vivo studies. Thromb Haemost 1993;70:1009-13.

44 Tetlow LC, Woolley DE. Comparative immunolocalization studies of collagenase 1 and collagenase 3 production in the rheumatoid lesion, and by human chondrocytes and synoviocytes in vitro. Br J Rheumatol 1998;37:64-70.

45 Tardif G, Pelletier JP, Dupuis M, Geng C, Cloutier JM, Martel-Pelletier J. Collagenase 3 production by human osteoarthritic chondrocytes in response to growth factors and cytokines is a function of the physiologic state of the cells. Arthritis Rheum 1999;42:1147-58.

46 Andrews HJ, Edwards TA, Cawston TE, Hazleman BL. Transforming growth factor-beta causes partial inhibition of interleukin 1-stimulated cartilage degradation in vitro. Biochem Biophys Res Commun 1989;162:144-50.

47 Shlopov BV, Smith GN Jr, Cole AA, Hasty KA. Differential patterns of response to doxycycline and transforming growth factor beta 1 in the down-regulation of collagenases in osteoarthritic and normal human chondrocytes. Arthritis Rheum 1999;42:719-27. 
48 Andrews HJ, Bunning RA, Plumpton TA, Clark IM, Russell RG, Cawston TE. Inhibition of interleukin-1-induced collagenase production in human articular chondrocytes in vitro by recombinant human interferon-gamma. Arthritis Rheum 1990;33:1733-8.

49 Brown TJ, Lioubin MN, Marquardt H. Purification and characterization of cytostatic lymphokines produced by activated human T lymphocytes. Synergistic antiproliferative activity of transforming growth factor beta 1 , interferon-gamma, and oncostatin $\mathrm{M}$ for human melanoma cells. J Immunol 1987;139:2977-83.

50 Hui W, Bell M, Carroll G. Detection of oncostatin M in synovial fluid from patients with rheumatoid arthritis. Ann Rheum Dis 1997;56:184-7.

51 Cowell S, Knauper V, Stewart ML, D'Ortho MP, Stanton $\mathrm{H}, \mathrm{Hembry} \mathrm{RM}$, et al. Induction of matrix metalloproteinase activation cascades based on membrane-type 1 matrix metalloproteinase: associated activation of gelatinase A gelatinase B and collagenase 3. Biochem J 1998;331(Pt 2):453-8.
52 Morales TI. The role and content of endogenous insulinlike growth factor-binding proteins in bovine articular car-
tilage. Arch Biochem Biophys 1997;343:164-72.

53 Rajah R, Katz L, Nunn S, Solberg P, Beers T, Cohen P. Insulin-like growth factor binding protein (IGFBP) proteases: functional regulators of cell growth. Progress in Growth Factor Research 1995;6:273-84.

54 Fowlkes JL, Serra DM, Nagase H, Thrailkill KM. MMPs are IGFBP-degrading proteinases: implications for cell proliferation and tissue growth. Ann N Y Acad Sci 1999;878:696-9.

55 Dore S, Pelletier JP, DiBattista JA, Tardif G, Brazeau P, Martel-Pelletier J. Human osteoarthritic chondrocytes possess an increased number of insulin-like growth factor 1 binding sites but are unresponsive to its stimulation. Possible role of IGF-1-binding proteins. Arthritis Rheum 1994; 37:253-63.

56 Schouten JS, Van den Ouweland FA, Valkenburg HA, Lamberts SW. Insulin-like growth factor-1: a prognostic factor berts SW. Insulin-like growth factor-1: a prognostic factor
of knee osteoarthritis. Br J Rheumatol 1993;32:274-80. 